Check for updates

\section{The BMJ}

Cite this as: BMJ 2021;372:n777 http://dx.doi.org/10.1136/bmj.n777 Published: 19 March 2021

\section{Covid-19: Doctors must be allowed to rest and recover for patients' safety, says BMA}

\section{Abi Rimmer}

Doctors must be allowed to rest and recuperate from the exhaustion of working throughout the pandemic so that the NHS can provide safe patient care in the future, the BMA has said.

In its latest report, the association called for the UK government to have an honest conversation with the public about the need for a realistic approach to restoring non-covid-19 care. ${ }^{1}$ It also called for the health, safety, and mental wellbeing of staff to remain a top priority.

"If staff are being pushed too hard to restore routine care in an unrealistic time frame and without suitable resources, the likelihood is that we will see a workforce squeeze due to a combination of increasingly high staff absence rates and staff reducing their hours or leaving the workforce altogether," the report said.

A survey conducted by the BMA in February found that, of the 7835 doctors who responded, 51\% (4010) thought that their overall health and wellbeing was worse than it was in the first wave of the pandemic. ${ }^{2}$ The report warned that the pressures of delivering care in a pandemic had not only compounded the existing wellbeing crisis but added further trauma and fatigue, as well as moral distress, to the daily working lives of doctors.

Chaand Nagpaul, BMA council chair, said that forcing doctors to get back to normal without respite and support would endanger patient safety and staffing ratios. "While some, exhausted and burnt out, might take more sick leave, others may decide to leave the NHS altogether," he said. "Fundamentally, asking too much of doctors too soon could not just have a detrimental impact on patient safety, it could potentially increase already lengthy waiting times-something both patients and doctors desperately want to avoid."

The BMA is also calling for additional resourcing to help tackle the backlog, measures to expand system capacity, and measures to expand the workforce and retain existing staff.

Listen to the BMJ Wellbeing podcast featuring Neil Greenberg on tackling post-traumatic stress disorder in the NHS: https://open.spotify.com/episode/ONIQoayiPm5hhmRcPka7KO?Si=3qY5Nzd2Swy_BVnGb5Cnew

BMA. Rest, recover, restore: getting UK health services back on track. https://www.bma.org.uk/media/3910/nhs-staff-recover-report-final.pdf BMA. BMA survey covid-19 tracker survey February 2021. https://www.bma.org.uk/media/3810/bma-covid-tracker-survey-february-2021.pdf

This article is made freely available for use in accordance with BMJ's website terms and conditions for the duration of the covid-19 pandemic or until otherwise determined by BMJ. You may use, download and print the article for any lawful, non-commercial purpose (including text and data mining) provided that all copyright notices and trade marks are retained. 